\title{
Lean Manufacturing of Pressure Valve Plate
}

\author{
Shradha M. Patil \\ Asst. Professor, Department of Mechanical Engineering, Fr. C. Rodrigues Institute of Technology, Vashi, Navi \\ Mumbai, Maharashtra
}

\begin{abstract}
Manufacturing of Pressure Valve Plate is considered as complex process that demands the knowledge of different areas, such as geometry, tolerances, dimensions, manufacturing procedures and manufacturing processes. Lean manufacturing avoids both setup time and setup cost of in manufacturing. Milling fixtures must be sturdy, with relatively large locating and supporting areas and strong clamp. Work piece deformation is unavoidable due to its elastic/plastic nature, and the external forces impacted by the clamping actuation and machining operations. Deformation has to be limited to an acceptable magnitude in order to achieve the tolerance specifications.

Accuracy of components like pressure valve plate is extremely essential. The analysis is carried out on fixture and pressure valve plate assembly. Pressure Valve plate fits on to hydraulic pump which is used to drive the engine load of defence vehicle. To study the fixture analysis and contact stress effect, fixture and valve plate are modelled and assembled for the analysis to be carried out.
\end{abstract}

Keywords: - Fixtures, Lean Manufacturing, Locators, Pressure Valve Plate, Setup time

\section{PROBLEM DEFINITION \& OBJECTIVE}

- Manufacturing of Pressure Valve plate with zero defects and minimum number of setups

- Fixture design to achieve higher accuracy of valve plate and minimise errors due to previous process

- Valve plate kidney port designed to provide minimum power loss and pressure pulsation throughout delivery

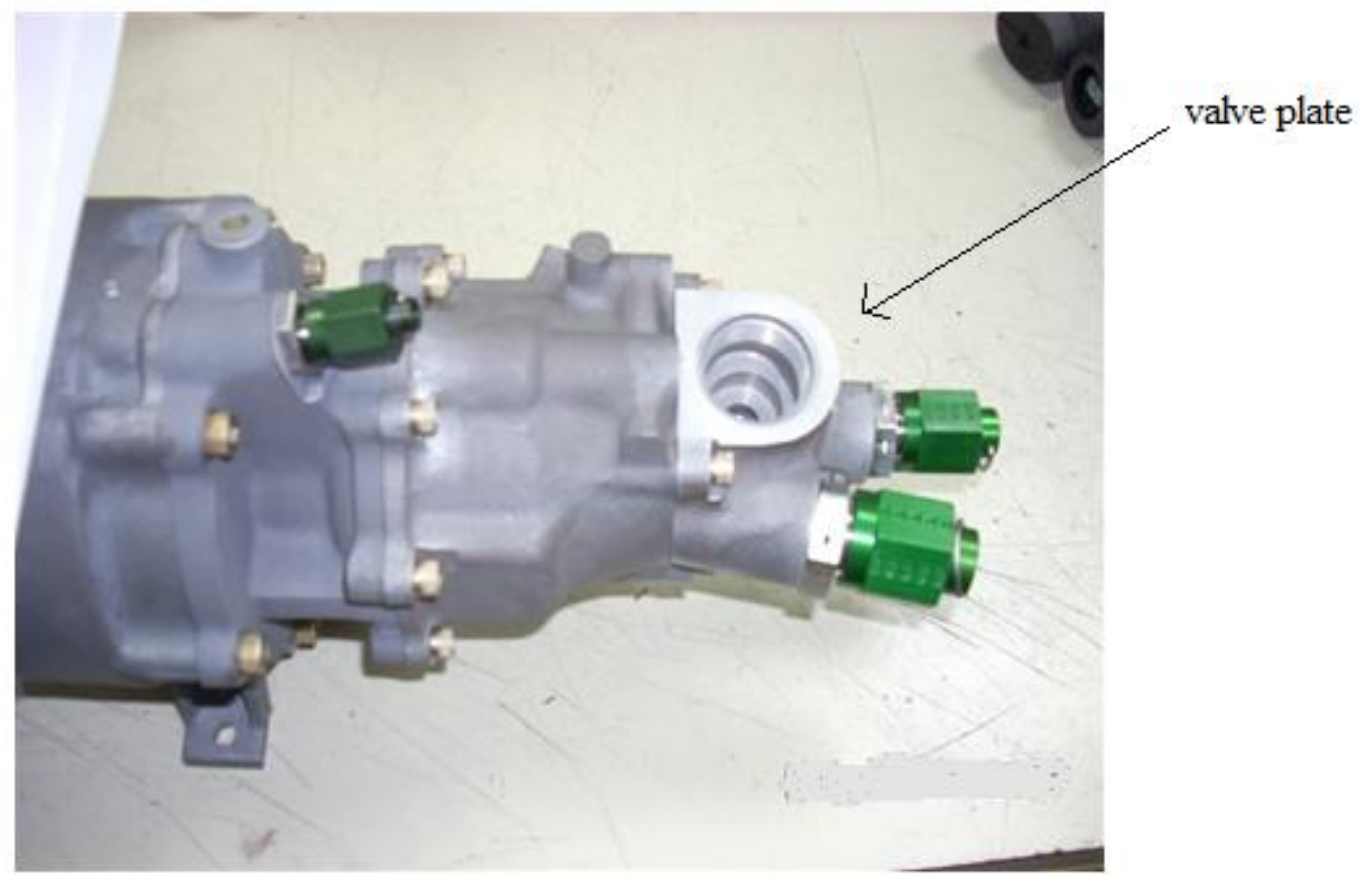

Fig1: Pressure Valve Plate

II. FIXTURE FOR REFERENCE MILLING AND DRILLING

Number of different fixtures was used to carry out the sequence of operations to achieve valve plate as per the requirement of EATON Pvt Ltd. The different operations (OP) carried out on valve plate are the following: OP20-Reference milling and drilling (1st setup)

OP30-Main milling (2nd setup) 
OP40-Milling of ports (3rd setup)

OP50-Finish machining setup

OP60-Break sharp edges to $0.25 \mathrm{~mm}$

OP70-Deburring

OP80-Marking for traceability

OP90-Inspection

OP100-Anodizing

OP110-Assembly

OP120-Pressure testing

The above following operations were carried out using different fixtures for different operations; the time required for each operation depends upon the setup time, loading of material, machining time, skill of labour, finishing operations and unloading of the part. Large number of operations on different faces of the component demands specific types of fixtures which can provide ease while machining.

Pressure valve plate was machined using fixture as shown in fig.1, this fixture contained two points for holding which is provided with help of screw and boss of valve plate is supported by fixture plate and clamped with help of bolt and nut, the operation OP20 carried out using this fixture was reference milling and drilling.

\subsection{Elimination of fixture for $\mathrm{OP} 20$}

Due to non-uniform and complex geometry of valve plate it is difficult to find the point of locating and holding the valve plate, and also the means by which the valve plate is supported or being hold, in the above case screw was provided for positioning the part and the operator was allowed to adjust the part. Due to manual adjustment and improper positioning, the valve plate while machining used to slide and move from its actual position which affected machining operation.

As this operation was initially done taking in account the drawing provided by the customer (EATON) but the final drawing of the valve plate does not include such a requirement. The unnecessary operation of reference milling and drilling was then eliminated as shown in fig 2.

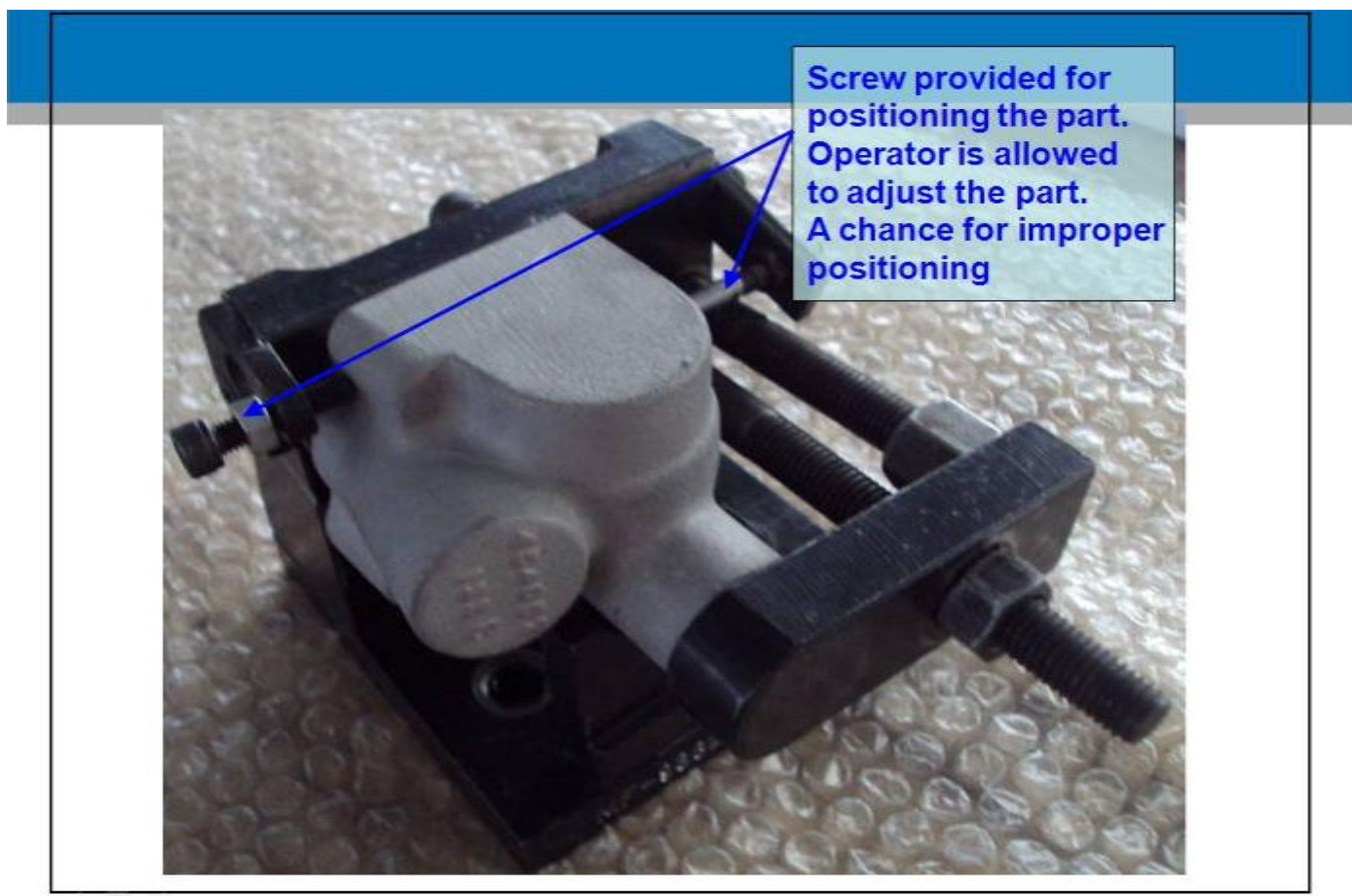

Fig 1: Fixture for reference milling and drilling

1. In the existing fixture the locating points are not taken as per drawing while designing the fixture

2. The target points given in the drawing are not considered for location

3. And the supporting / resting face is not considered as per drawing 


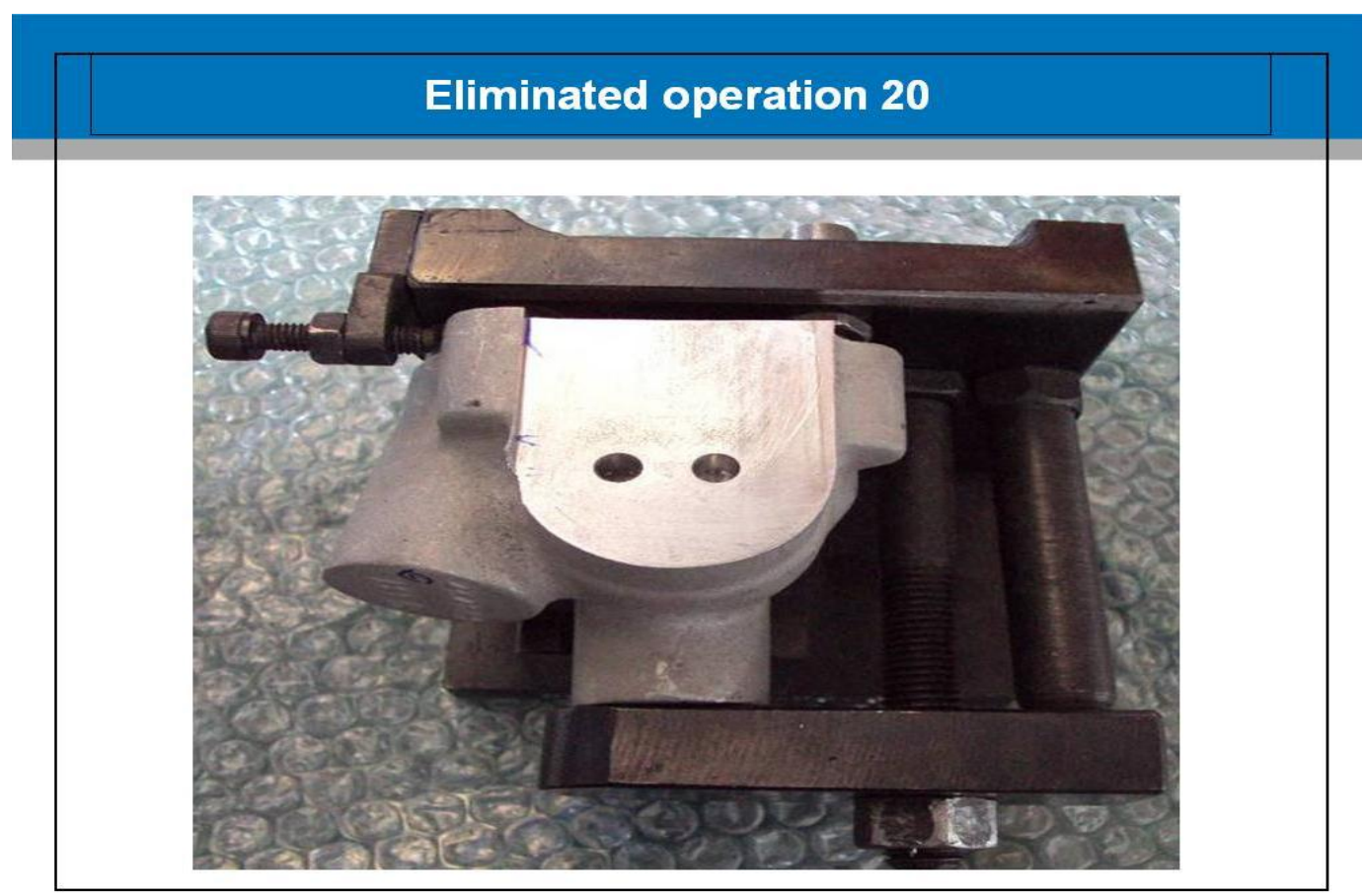

Fig 2: Eliminated operation 20 and fixture setup

\subsection{Fixture for milling 2 nd setup}

Fixture for holding valve plate casting while carrying out OP30 (milling), the valve plate is held and supported with the help of the nut and bolt at one end and is rested at the other end as shown in fig.3. In the existing fixture, the valve plate is supported with nut and bolt on the cylindrical surface due to which the valve plate tilts while carrying out the machining operation and tends to cause error in the dimensions of valve plate, which increases the rejection rate, machining cost and machining time. The bolt provided for supporting the valve plate was adjustable and mainly depends upon the operator's skill while fixing the valve plate in fixture. The placing of valve plate too tightly by nut and bolt adjustment causes deviation while machining which again leads to error.

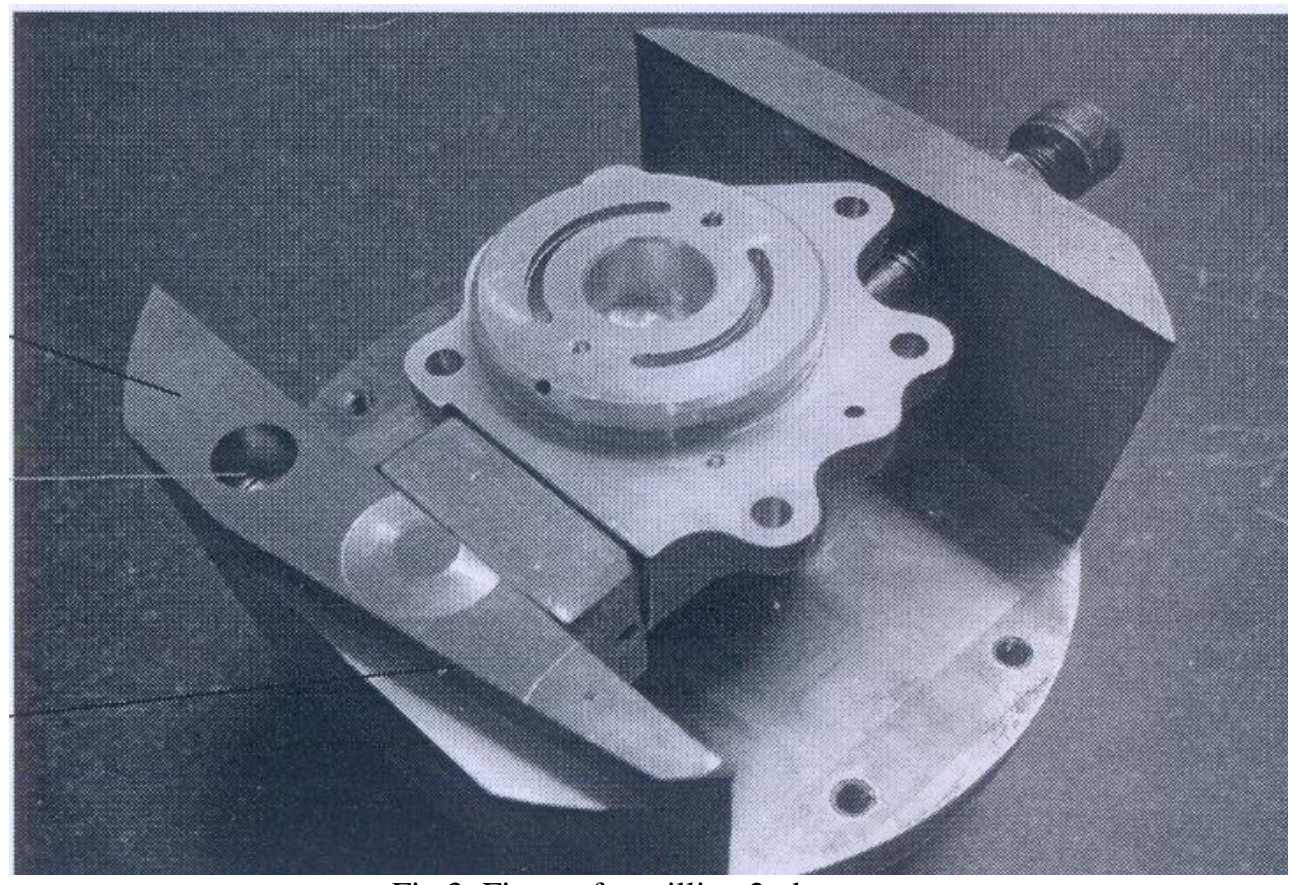

Fig 3: Fixture for milling 2nd setup 
III. DETAILED DRAWING AND SPECIFICATIONS OF NEW FIXTURE AND ITS PARTS

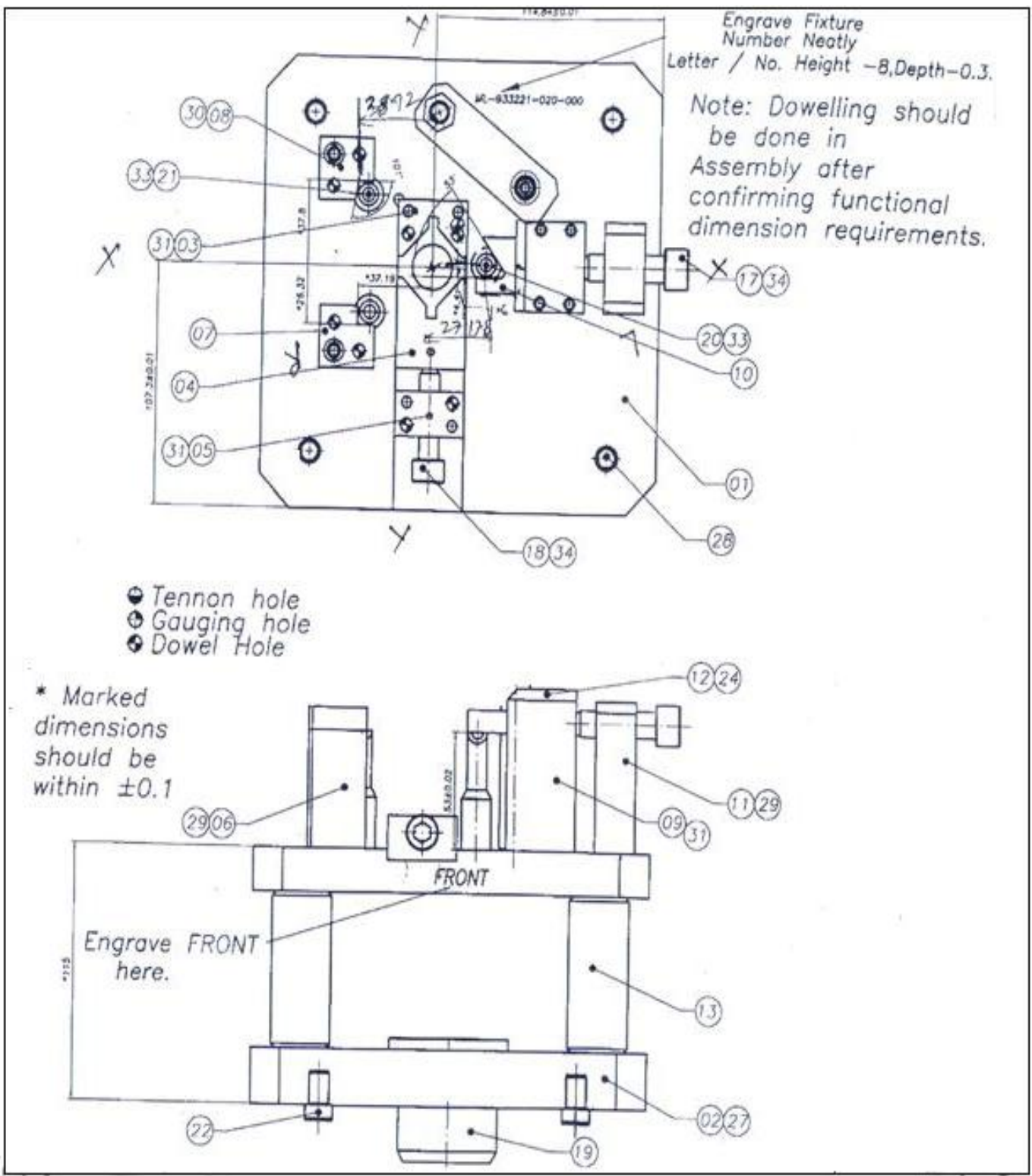

Fig 4: Detailed drawing of fixture assembly

Different parts of fixture:

- Height block

- Base plate

- Block for clamping

- $\quad$ Fixed locators

- Bottom plate

- Top cover

- Resting pillar

- Pins for support

- $\quad$ Fixed V-clamp 


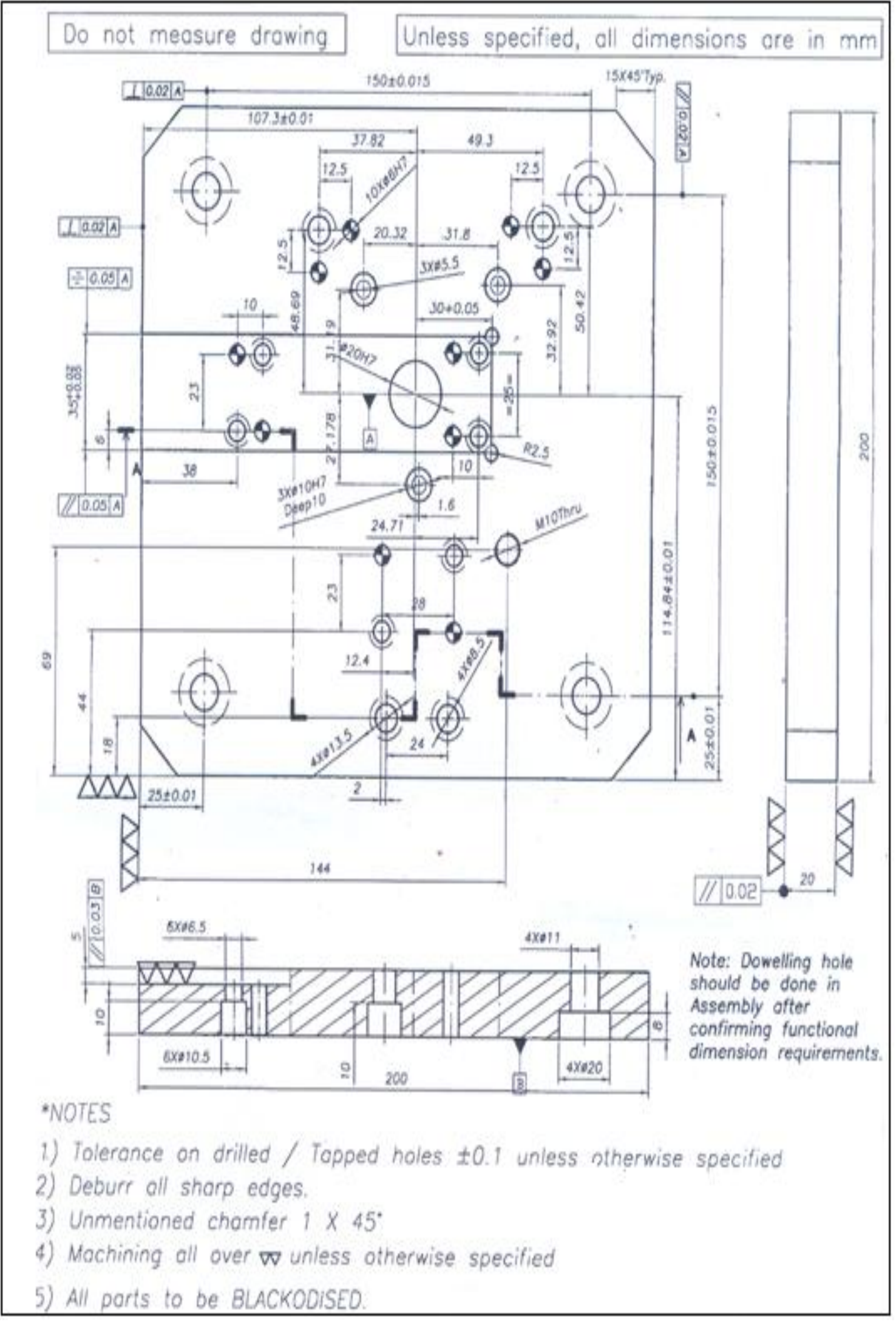

Fig 4a: Drawing and specifications of base plate 


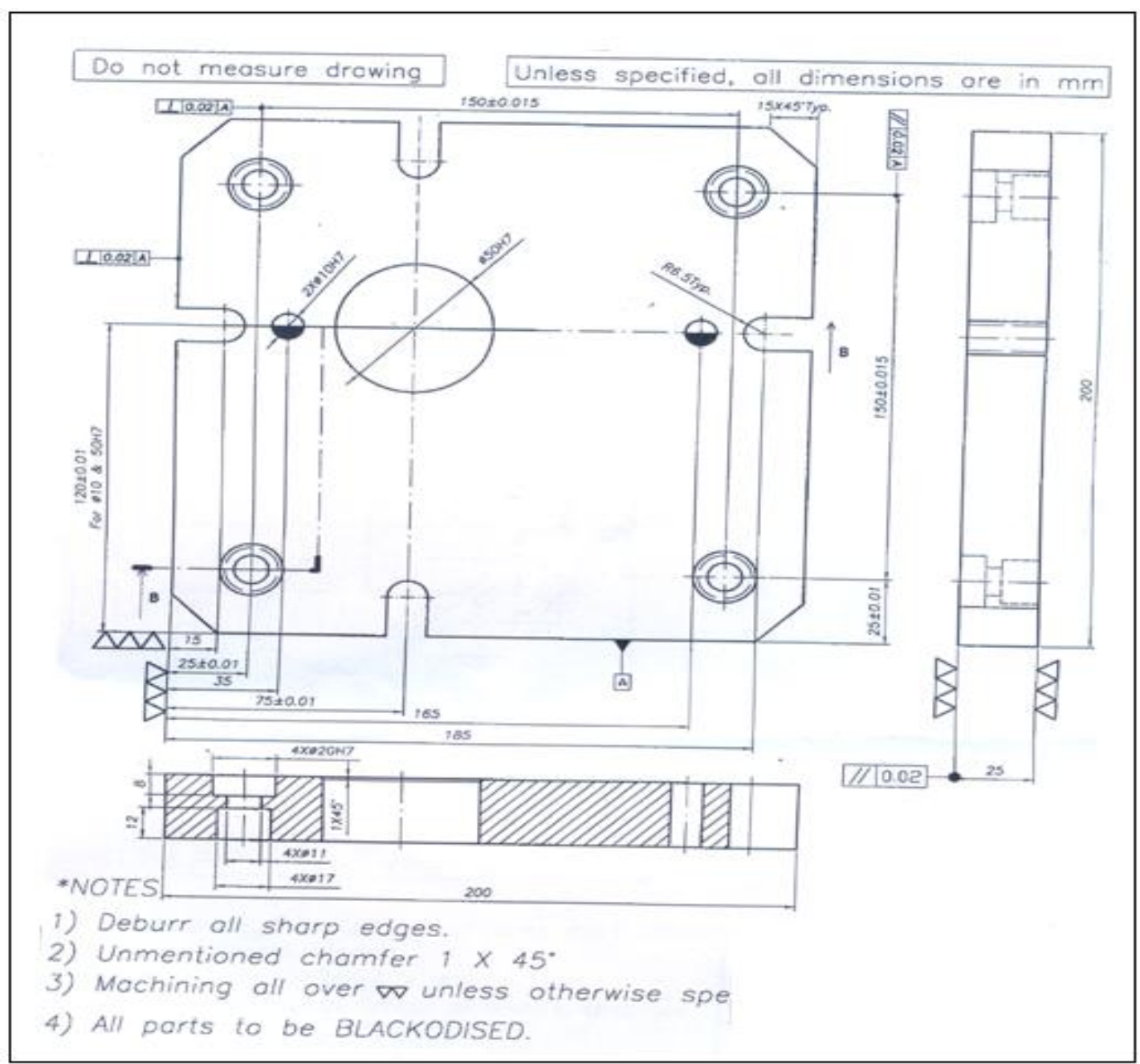

Fig 4b: Drawing and specifications of bottom plate

IV. REDUCTION IN NUMBER OF SETUPS AND CONSTRUCTION OF NEW FIXTURE

Fixture for reference milling and drilling (OP20) is eliminated as the final geometry of the valve plate does not demand such a requirement, thus reducing the $1^{\text {st }}$ setup which saved machining cost and time, which also ensure on time delivery and customer satisfaction. OP20 is replaced by $2^{\text {nd }}$ machining setup with new fixture and sequence of operations. The revised sequence of operation is given below:

OP20-Milling (1st setup)

OP30-Milling of ports (2nd setup)

OP40-Finish machining setup

OP50-Break sharp edges to $0.25 \mathrm{~mm}$

OP60-Deburring

OP70-Marking for traceability

OP80-Inspection

OP90-Anodizing

OP100-Assembly

OP110-Pressure testing

Therefore a corrective action is taken and a new fixture is designed as shown in fig.5 with the help of following considerations:

1. The new fixture made as per the conceptual design with the help of tool design

2. Target points and resting/supporting points considered as per the part drawing

3. Manual adjustment by operator not permitted

4. Two fixed locators and one adjustable locator provided

5. CNC program changed to suit the new process 


\section{Opn-20 with new fixture}

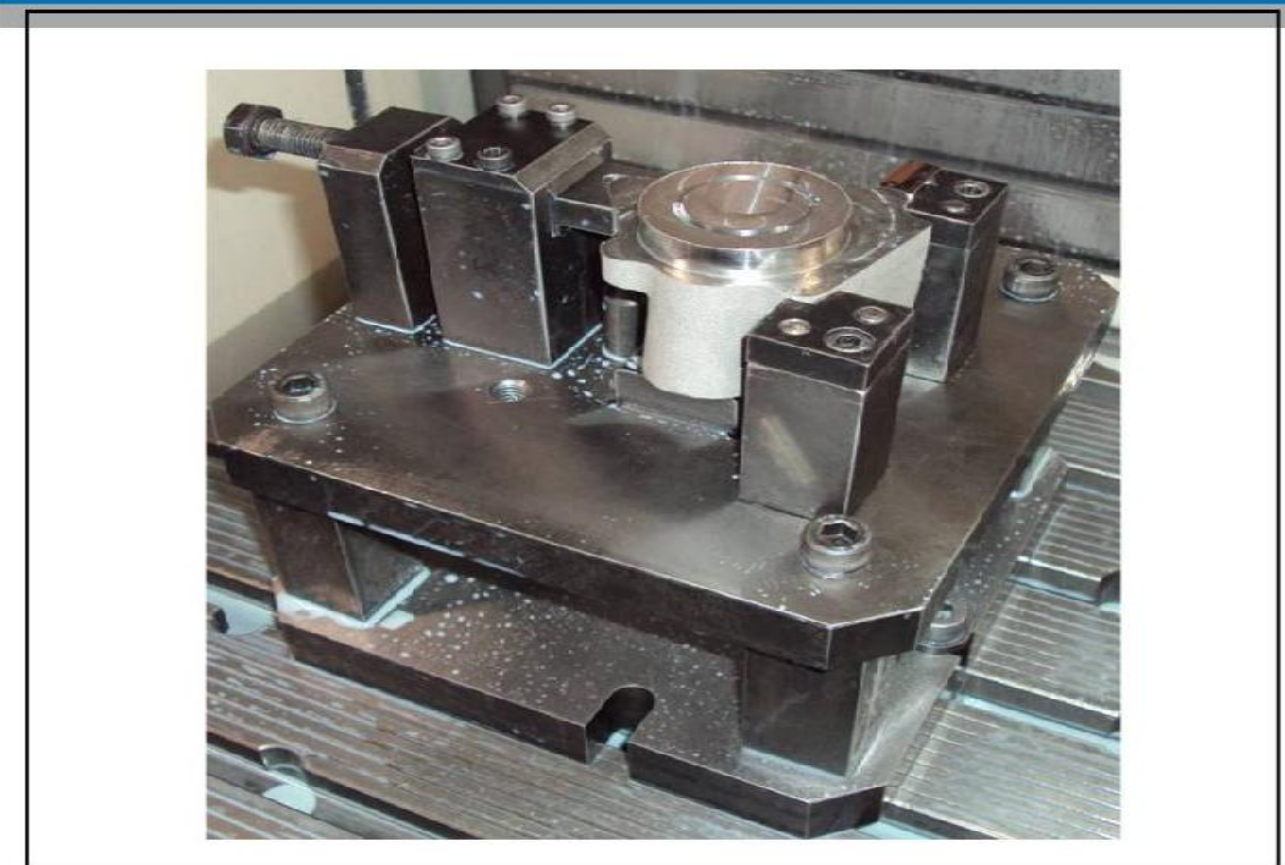

Fig 5: New fixture for OP20

The new fixture is implemented and the casting was properly placed and located in this fixture, the results found were better than previous results and there were less rejections. The new fixture not only improved the quality but also eliminated operation 20 which is not required on the final part. This had directly saved the set up time of $45 \mathrm{~min}$ and machining cycle time of $37 \mathrm{~min} /$ part also the skill operator for setting the part on the fixture is not required. Fig.6 shows new fixture design holding pressure valve plate. Target points at which component (valve plate casting) comes in contact with fixture is shown in fig 7.



Fig.6: Fixture for holding valve plate 




Fig.7: Casting of valve plate

V. INVESTIGATION AND ANALYSIS OF VALVE PLATE

The outlet port of valve plate after completing the machining operation was found with an error due to eccentricity leading to low wall thickness of 0.0625 inch to 0.0630 inch as shown in fig 8 , whereas the required wall thickness is $0.075 \mathrm{inch}$

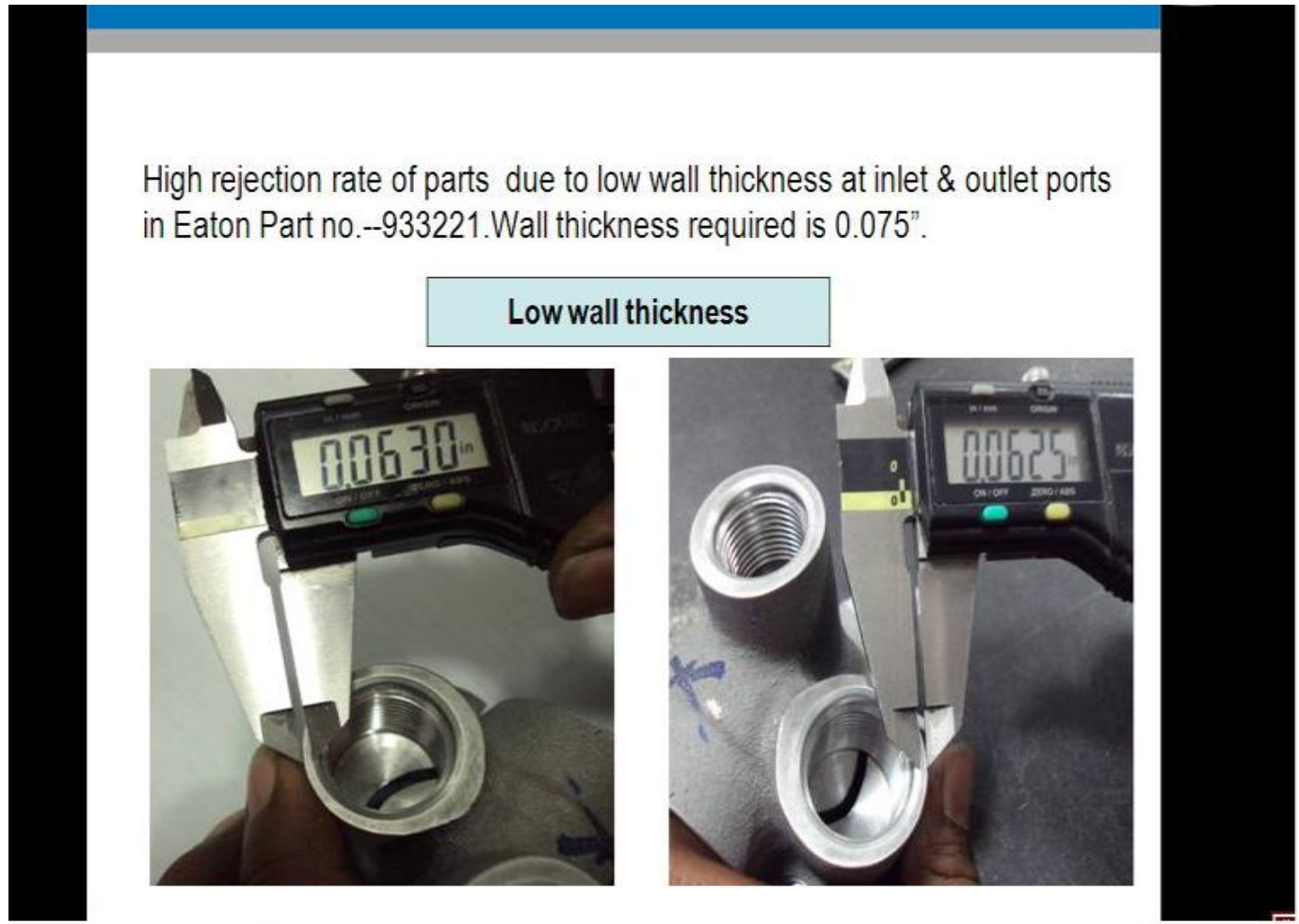

Fig.8: Valve plate outlet port 
Initially the casting is investigated and there are no error in the casting as per the drawing, but the port angle of 12 degree is observed as 11 degree, which contributes to the deviation of low w/t ratio though the casting is correct as per its drawing also the other dimensions were found correct.



Fig.9: Valve plate outlet port line diagram

\section{CAUSE AND EFFECT}

The deviation in angle of the outlet port contributes to low wall thickness which means the tooling provided is not correct, some of the observations regarding the tooling as shown in fig 10 are:

1. The fixture is not positioning the part at required position while carrying out the operation

2. The locating pin provided on the fixture was undersize by $0.3 \mathrm{~mm}$

3. The position of pin was offset by $0.15 \mathrm{~mm}$

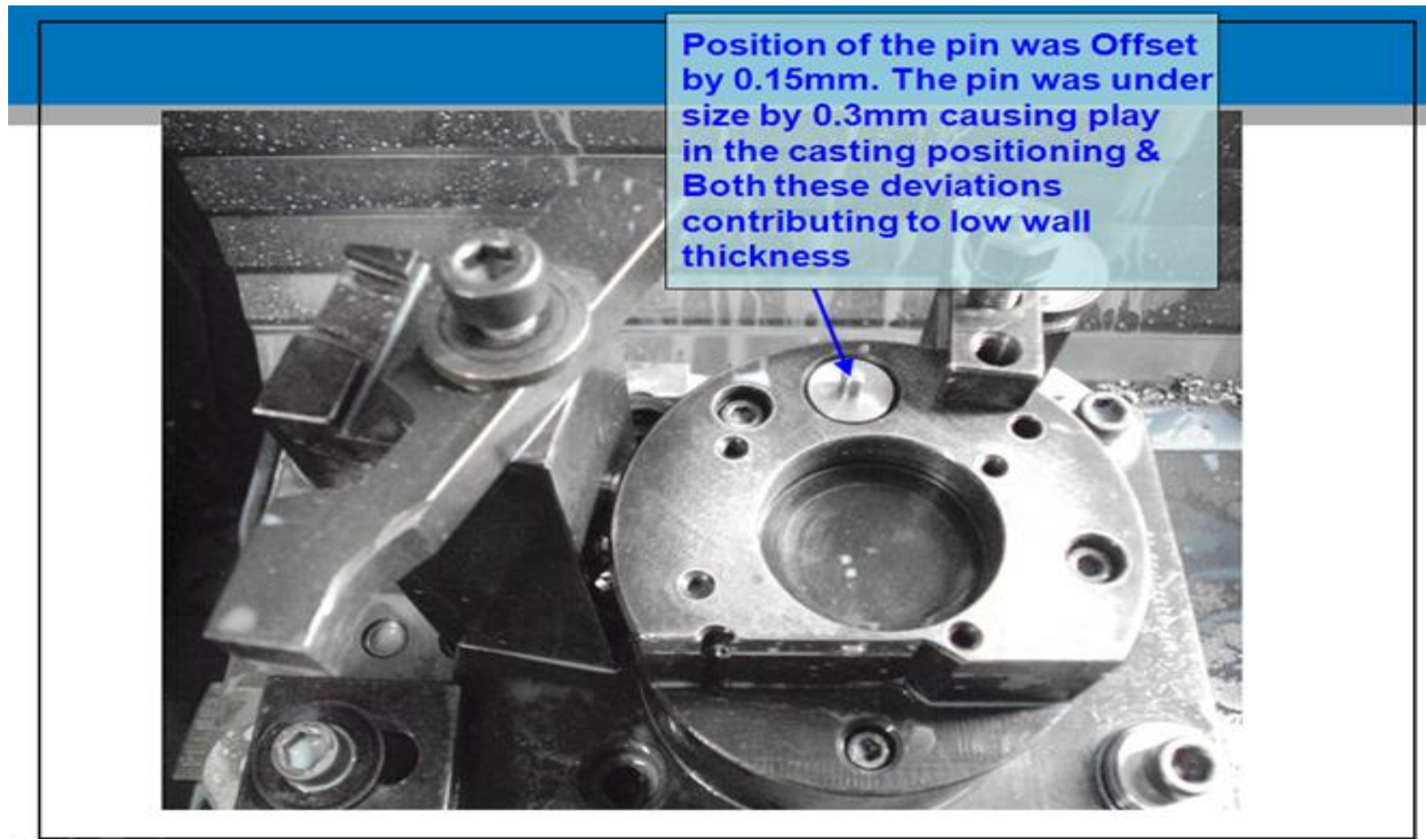

Fig 10: Fault in fixture 


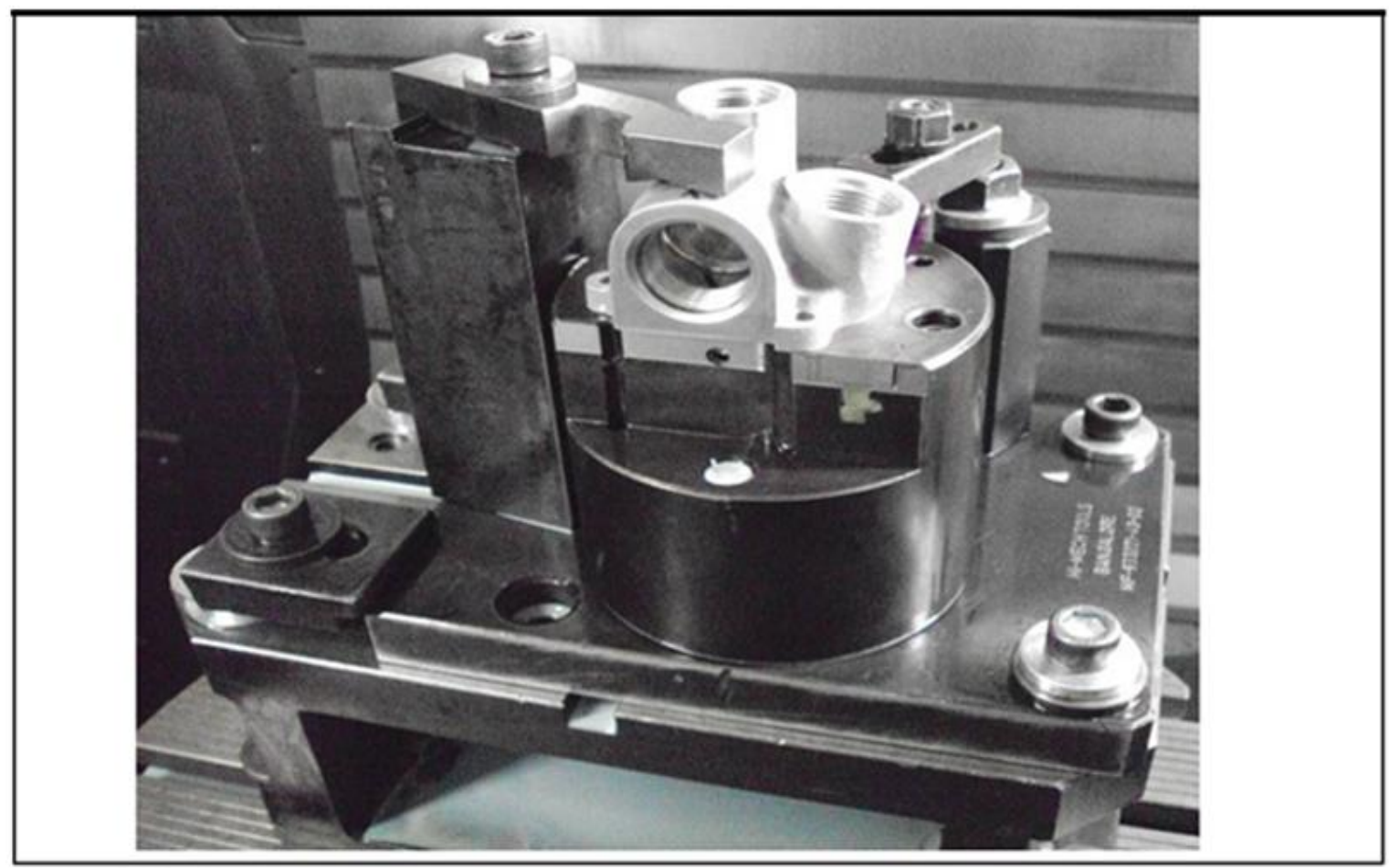

Fig 11: Corrected fixture

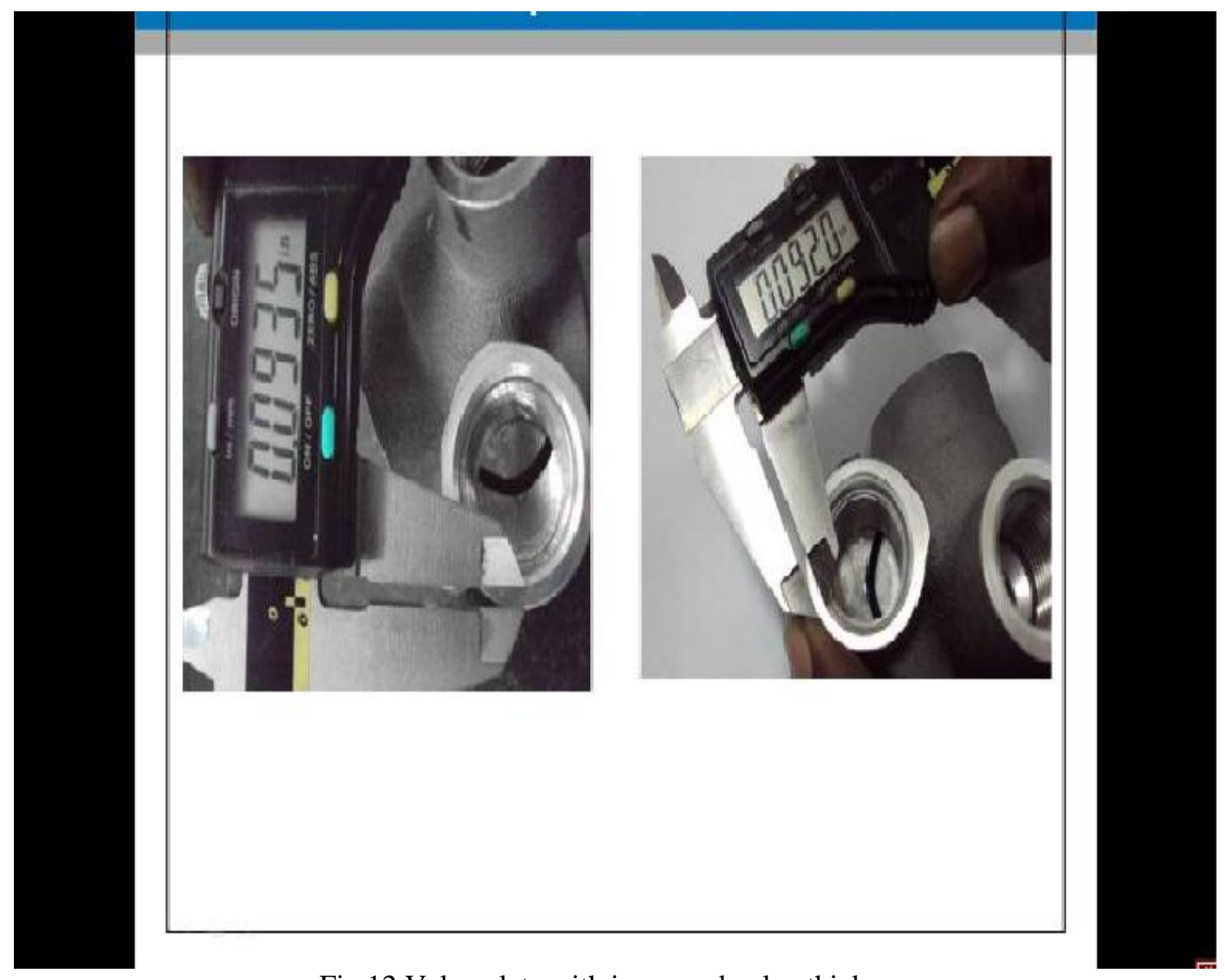

Fig.12 Valve plate with improved valve thickness

With reference to fig. 12 it can be seen that wall thickness has increased from a range of $0.625-0.630$ to 0.920 0.935 due to which the rejection rate has been minimized. 


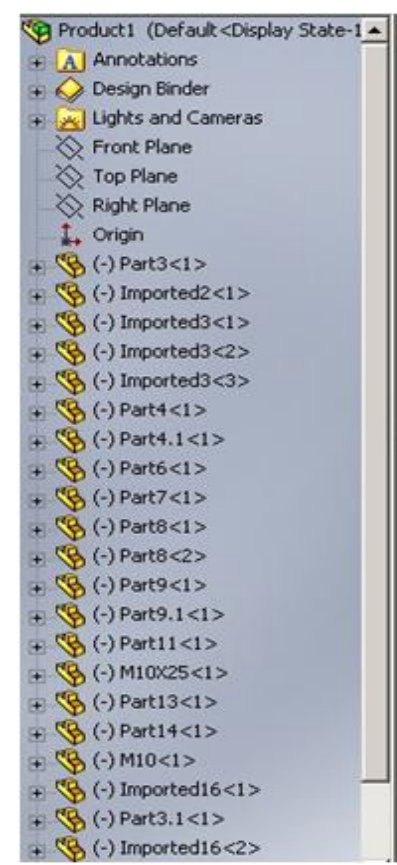

Fig.13: Catia Model of valve plate and fixture assembly

VII. CONCLUSIONS

1. The changes made in fixture design eliminated the error of low wall thickness while manufacturing the valve plate.

2. Fixture design has helped to reduce the number of setups and thus reducing the machining cost and time.

3. The new fixture not only improved the quality but also eliminated OP20 which is not required on the final part.

4. Valve plate kidney port designed to provide minimum power loss and pressure pulsation throughout delivery

5. The Catia V5 software has shown good agreement in this work giving good 3D model for analysis and its results.

\section{ACKNOWLEDGEMENTS}

The satisfaction and euphoria that accompany the successful completion of any task would be incomplete without the mention of people who made it possible, whose constant guidance and encouragement crowned my effort with success.

With immense sense of gratitude I greatly acknowledge my parents Mr. Jaysing-rao Kaktikar and Mrs. Alka Kaktikar my guide, Mr. Sreeram .K Sr.Manager QuEST-Global Manufacturing Pvt Ltd, Mr. Appasaheb .B Tool design lead and Asst. Professor Amith H.Gadagi, KLE's Society College of Engineering and Technology Belgaum, whose inspiration, encouragement and immense support made this dissertation work successful!

\section{REFERENCES}

[1] "The five steps of fixture design", by Ray Okolischan, Cutting tool Engg, Aug 1996

[2] "Design of machine tools" by S.K Basu and D K. Pal

[3] "A Descriptive Summary of Vickers Inline Pumps and their Applications"

[4] "Fundamentals of Machining and Machine tools" by R.K Singal, Mridul Singal and Rishisingal Aug 2000

[5] http://www. Eaton hyd aerospace/valve plate/summary.pdf

[6] www.Eaton.com

\section{Author}

I undersigned Shradha M. patil working as Assistant. Professor in Fr.CRIT, Vashi, Navi Mumbai, is graduate in Industrial Production from Gogte Institute of Technology, Belgaum, Karnataka and Post Graduate in Design Engineering from KLECET, Belgaum, Karnataka. I have been in teaching for four years and completed training with QuEST-Global Manufacturing Pvt. Ltd (Aerospace firm) Belgaum for one year. I am Enthusiastic in future for still more research and developmental activities in the field of Mechanical Engineering. 